\section{Adolescent units}

Sir: I welcome Peter Wells' comments in 'Adolescent Units-whither on the vine?' (Psychiatric Bulletin, April 1995, 19, 248249) and wholeheartedly agree with his concerns. I also welcome the news that the Department of Health will be commissioning further needs assessments, data collection and research concerning adolescent mental health.

An additional factor that may be producing adolescent unit 'withering' is money. The reforms encourage financial accountability and there has been a strong tendency to attack large budgets (in this case in-patient services) as a first step. These services are also the ones whose efficacy it is difficult to prove. However the tide may be turning. Purchasers are rapidly learning that out-patient services are unable to cope with highly disturbed and often dangerous adolescents and, in the absence of skilled and competent resources to manage them, are facing very large bills from private establishments.

For our unit (Hill End Adolescent Unit) and in our region (North Thames West) the situation does indeed seem to be changing. Having temporarily closed to in-patients with the retirement of our consultant, the unit is now fully functioning and is blessed with a plentiful supply of referrals. In addition, the region which once supported three in-patient adolescent units now has four and may soon have five! While the development of in-patient services ought to take place within an overall plan for child mental health, these changes seem to represent a tide that is to be welcomed and should continue to flow.

ANDREw HILL-Smrth, Specialist Psychiatric Unit for Adolescents, West Herts Community Health (NHS) Trust, Hill End Hospital, St Albans ALA ORB

Editorial note. We have been advised by S. Thacker that in his letter (Psychiatric Bulletin. September 1995, 19, 575) he referred to material currently in press for the International Journal of Geriatric Psychiatry.

\section{Traditional healers}

Sir: Dr Patel provides an interesting glimpse into how traditional healers (TH) work in Zimbabwe (Psychiatric Bulletin, May 1995, 19, 315-316). There is no doubt that these TH play an important role in the treatment of many psychological disorders. In societies where it is still considered to be a stigma to see a psychiatrist, the existence of these $\mathrm{TH}$ can hardly be denied. In many third world countries like Pakistan these $\mathrm{TH}$ have a dominant influence on the cultural and religious belief systems of the people especially those who live in the rural community. These $\mathrm{TH}$ not only have close contact with the rural elite but they also affect the way people think about their problems.

Despite being aware of the unscientific and sometimes illiterate background of these TH, the people still hold them in high esteem. It is because of this that these healers succeeed in exploiting the people on the basis of their cultural beliefs. Their multi-faceted role makes them quite powerful and some of them see a far greater number of patients than a hospital based psychiatrist. Some of these TH are quite good at treating the minor disorders especially the psychosexual and psychosomatic disorders. Unfortunately when it comes to the major psychotic illnessses, a real problem ensues. Most of the TH patients are not only badly mismanaged but some end up having long-term complications. It is through this channel that sometimes a formal psychiatric service gets involved. However, sometimes these TH themselves advise the families to take their patients to the hospitals saying that they have dealt with the demons and witchcraft and now it is the job of the doctors to repair the physical damage.

I agree with Dr Patel that there is a need to be more open about the role and significance of the traditional sector and I also feel that there should be good working relationships between the traditional and biomedical healers. However, one must not forget that too much dependence upon these TH can sometimes be quite devastating. Unless the general awareness of the public about their own 
psychological difficulties within their own cultural framework improves, it is very difficult to expect a dramatic change in the existing system. In fact any such efforts will be quite futile.

RAMEEZ ZAFAR, Lincoln District Healthcare NHS Trust, Peter Hodgkinson Centre, County Hospital, Lincoln LN2 5QY

\section{Examination techniques}

Sir: We share the concerns of Dr Donnelly in his description of the problems that junior psychiatrists often have in passing the MRCPsych clinical examinations (Psychiatric Bulletin, May 1995, 19, 302-304). We believe that very good candidates sometimes fail more because of poor examination technique than a lack of knowledge or clinical skills. On the MCQ papers it is possible to score $74 \%$ of answers correctly yet because of negative marking' a net mark of only $48 \%$ may be achieved if every other response is wrong.

Other aspects of the exams illustrate the same point; having good levels of knowledge and clinical skills may not be enough to pass. The ability to present essays, SAQs, PMPs and the clinical case in an organised and professional manner is not one that comes naturally to everyone. These are skills that need to be practised and developed.

It is our experience, in teaching candidates in Yorkshire, that specific teaching of examination technique is sometimes overlooked by candidates and trainers alike. Within the setting of the Leeds Examination Techniques Course (which is run twice yearly) candidates are offered clear teaching in case presentation, and practise in each area of the written exam (Williams et al, 1995). The purpose of the course is not to teach facts about psychiatry (it is the responsibility of each candidate to learn these), but to encourage each candidate to present what they do know effectively. The skills required in the exam are also the skills of a good psychiatrist; to effectively gather, organise and integrate information in order to decide on appropriate treatment approaches.

Learning factual knowledge and clinical skills alone, although important, is not enough. We would encourage all trainees and trainers to be aware that candidates need to practise specific exam techniques as well, so that they can communicate these skills effectively.

Willams. C. J., Trigwel., P. \& Yeomans, J. D. I. (1995) Pass the MRCPsych Parts I and II (All the techniques you need). London: Baillière Tindall/WB Saunders.

Chris Williams, David Yeomans and Peter TRIGWELl, St James's University Hospital, Leeds LS9 7TF

\section{Mental Health Task Force Support Group}

Sir: Reading the briefing on the Mental Health Task Force Support Group by Wattis \& Thompson (Psychiatric Bulletin. April 1995, 19, 250-251), we are unsure as to how they have advanced the "cause of services for people with mental illness". One has the impression that there had been much consultation with 'user groups' and the publication of many documents - but to what effect, other than guidelines suggested elsewhere? Mention was made of the newsletter Grass Roots, supposedly circulated to notify people of the work of the Task Force, but it was unknown in the psychiatric hospital where we work.

The Task Force was set up to "help ensure the substantial completion of the transfer of services away from large old-style hospitals to a balanced range of comprehensive locallybased services" (Jenkins, 1994). However we suspect that this was a government quango set up to provide little more than a public relations exercise. We would be interested to hear of any tangible benefits of the Mental Health Task Force others have observed.

JENKINS, R. (1994) The Health of the Nation. recent government policy and legislation. Psychiatric Bulletin. 18. 324-327.

STEVEN REID and JOANNE TURNER, Springfield Hospital, 61 Glenburnie Road, London SW17 7DJ

\section{Interaction between staff of psychiatric intensive care units}

Sir: There is very little formal interaction between staff of psychiatric intensive care units (PICU), e.g. at College level. Unlike 